\title{
Von der Fach- zur Management-Karriere?
}

\section{Liebe Leserinnen und Leser,}

trifft man heute Controller in intensiver Diskussion an, so darf man fast sicher sein, dass es dabei um das Thema Business Partnering geht. Jeder Controller scheint Business Partner werden zu wollen. Von außen betrachtet ist es sehr erstaunlich, wie schnell sich diese Perspektive in Deutschland durchgesetzt hat. Noch vor Kurzem war das international gut zehn Jahre alte Konzept unter deutschen Controllern gänzlich unbekannt. Zwar gab es auch bei uns mit dem „betriebswirtschaftlichen Begleiter“ seit Langem ein Rollenbild mit ähnlichem Inhalt. Es hatte aber weit weniger Zugkraft auf die Controller ausgeübt. Erst - und wieder einmal - mit einem englischen Begriff kam es zur aktuellen Aufbruchsstimmung. Kein Controller scheint sich daran zu stören, dass sich auch andere Funktionen mit dem Titel des Business Partners zu schmücken versuchen, so z. B. die HR- und die IT-Abteilung. Die neue Zielrolle ist einfach zu „sexy“. Sie klingt zugegebenermaßen deutlich schöner als die des betriebswirtschaftlichen Begleiters. „Partner“ steht für gleiche Augenhöhe mit dem Management und „Business“ für konkreten Impact des eigenen Handelns, nicht für rechnende Hilfstätigkeiten. Nun können auch Controller helfen, das Unternehmen geschäftlich voranzubringen, also „big-business“ zu machen. Controller fühlen sich so mitverantwortlich für den geschäftlichen Erfolg, sie sehen sich in einer Linie mit dem Management, stehen also quasi mit an vorderster Front.

So weit der Anspruch. Und wie steht es um seine Einlösung? Wie viele Controller sind schon beim Business Partner angekommen? (Wir haben von zehn Prozent ebenso gehört wie von 50 Prozent und mehr.) Sollte sich überhaupt jeder auf den Weg dahin machen? Brauchen die Unternehmen nicht auch Spezialisten, die sich im Detail mit den betriebswirtschaftlichen Zahlen auskennen und die komplexe Steuerungsprozesse aus dem Effeff beherrschen?

Hinter diesen Fragen steht eine ganz zentrale Weggabelung, an der die Controller angekommen sind. Wenn wir an Controllerpositionen in der Zukunft denken, werden wir diese ganz traditionell - in einer finanzbezogenen Fachkarriere sehen, oder werden wir stattdessen Controller antreffen, die

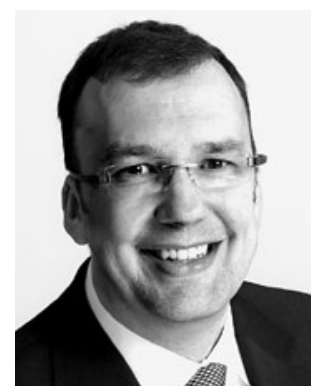

Utz Schäffer

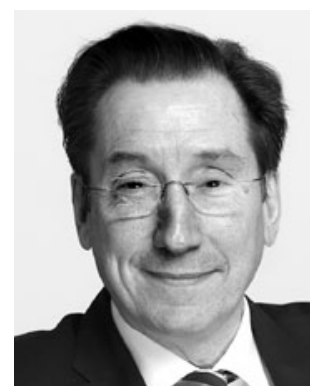

Jürgen Weber gerade eine Position innerhalb einer Managementkarriere ausüben? Wer Business Partner der Manager sein will, muss denken und handeln können wie ein Manager. Tiefe Geschäftskenntnisse sind ebenso unverzichtbar wie der Wille, den Erfolg des Unternehmens voranzutreiben. Eine hohe fachliche Spezialisierung in Richtung betriebswirtschaftlicher Methoden und Instrumente ist damit nur schwer vereinbar. Die durchschnittliche Zeit eines Managers in einer Position ist zu kurz, um dieses Spezial-Know-how zu erwerben. Wer den Business Partner als Zielrolle vor Augen hat, muss sich bewusst sein, dass damit der Weg bereitet wird, Fachkarrieren gegen Managementkarrieren einzutauschen. Auch in anderen Segmenten (z. B. im Accounting- und Tax-Bereich) greifen Unternehmen längst bei kniffligeren Fragen auf Expertise von außen zurück. Wird das die schöne neue Welt des Business Partners?

Viel Spaß bei der Lektüre wünschen Ihnen

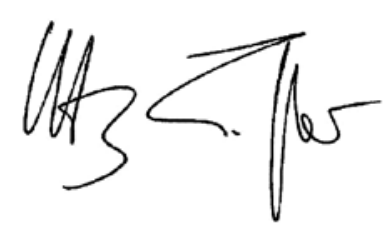

Utz Schäffer

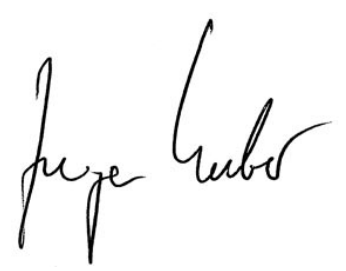

Jürgen Weber 